\title{
Posttraumatic Stress Disorder (PTSD) among Male Adolescents in Baghdad
}

\section{Riyadh K Lafta ${ }^{1 *}$, Zaidoon S Aziz ${ }^{2}$ and AbdulKareem AlObaidi ${ }^{3}$}

${ }^{1}$ Professor in Community Medicine, Mustansiriya University, College of Medicine, Baghdad, Iraq

${ }^{2}$ Community Medicine, Ministry of Health, Baghdad, Iraq

IInstitute for International Education (IIE), NY, USA

\begin{abstract}
Background: Posttraumatic Stress Disorder (PTSD) among adolescents is increasing worldwide especially in violent conflicts and war zones. Iraq is consistently exposed to large-scale traumatic events such as successive wars, economic sanction, sustainable organized violence, and terrorism. This unsafe situation negatively impacts on the psychosocial status of the whole Iraqi community, especially children and adolescents.
\end{abstract}

Objective: To assess the prevalence of PTSD in a sample of adolescents in Baghdad, and to figure out the probable association between some socio-demographic characteristics and PTSD symptoms.

Methods: A sample of 1858 male students, aged 13 to 19 years, was selected from 18 secondary schools for boys in Baghdad. The Arabic version of the International Neuropsychiatric Interview PTSD module 'I' (M.I.N.I) was adopted to assess the presence of PTSD symptoms.

Results: Trauma experiences were reported by more than $55 \%$ of the sample surveyed and $17.1 \%$ reported symptoms of PTSD. Higher rates of PTSD occurred among adolescents aged $17-19$ years $(24.7 \%)$ and among those whose fathers were deceased and those who living with non-biological caregivers.

Conclusion: The unsafe situation in Iraq has led to high trauma exposure and a high prevalence rate of PTSD among Male Adolescents in Baghdad. The study explored a number of factors that are associated with this increased rate. The data generated from this study may be of use to policy makers, people work in mental health care as well as practitioners in the field.

Keywords: PTSD; Boys; Baghdad; Secondary schools

\section{Introduction}

Posttraumatic Stress Disorder (PTSD) is widely understood as an extreme psychological reaction that follows severe traumatic events $[1,2]$. The developmental immaturity of youth increases their vulnerability to the devastating sequels of PTSD following traumatic events such as poor health, poor quality of life, and subsequent comorbid emotional/behavioral problems [3]. The research literature indicates that males are more often exposed to traumatic experiences than females [4].

Globally, a wide range of studies document high rates of PTSD among children and adolescents in violent conflicts and war zones $[5,6]$. For example, in Bosnia, the PTSD rate is $41 \%$ for children age 6-16 year [7]. A study of children in Rwanda found that $54 \%$ to $62 \%$ of children had PTSD with a rate of $72 \%$ for males [8]. Rates of PTSD in Palestinian school children range from 39-87\% [9-11]. PTSD rate reported among children males in Afghanistan is 32\% [12]. In another study on children in Kabul (Afghanistan) a higher prevalence of PTSD was shown in boys (26\%) compared to $14 \%$ in girls [13]. In a UK study, PTSD was associated with the cumulative effects of pre- and postimmigration stressors among asylum-seeking male adolescents from Afghanistan, the researchers in this study suggested that $34 \%$ of the male adolescents were likely to have PTSD [14].

Iraq is consistently exposed to large-scale traumatic events such as successive wars (since 1980 to present), economic sanction, sustainable organized violence, and terrorism. This unsafe situation negatively impacts on the psychosocial status of the whole Iraqi community [15], especially children and adolescents [16]. In Iraq children and adolescents below 18 years form half of its population of approximately 33 million [17]. There is paucity of standardized research data about the extent of child and adolescents' mental health problems to inform policy planning and to practice development [18]. WHO reported that only
$2 \%$ of all health research in Iraq conducted during 2000-2005 addressed mental health issues [19]. Child and Adolescent Mental Health Services (CAMHS) in Iraq are almost non-existent. Psychiatrists formally trained in child and adolescent mental health are few in number, and the stigma associated with mental disorders is pronounced. The Iraqi school system currently lacks a mental health philosophy: there is no school-based CAMHS. Iraqi teachers are not trained to identify children with learning and/or emotional problems [20].

Iraq is an exemplar of the challenging mental health needs of children and adolescents in low-income, conflict -affected countries. Empirical data-based research is needed to measure the impact of traumatic psychosocial experiences upon children and adolescents' health in conflict areas like Iraq starting with measuring the prevalence of PTSD. We couldn't find any estimates about the prevalence of PTSD in Iraqi male adolescent populations before the 2003 war.

This was the rationale behind conducting this study as the psychological trauma is increasing in Iraq as a result of the successive wars/violence, yet, there is little attention to it, moreover, the lack of psychological and mental health services in Iraq makes this problem more serious especially that it is affecting this vulnerable group.

*Corresponding author: Riyadh K Lafta, Professor in Community Medicine Mustansiriya University, College of Medicine, Baghdad, Iraq, E-mail: riyadhlafta@yahoo.com

Received May 15, 2014; Accepted June 04, 2014; Published June 14, 2014

Citation: Lafta RK, Aziz ZS, AlObaidi AK (2014) Posttraumatic Stress Disorder (PTSD) among Male Adolescents in Baghdad. J Psychol Abnorm Child 3: 121. doi:10.4172/2329-9525.1000121

Copyright: $\odot 2014$ Lafta RK, et al. This is an open-access article distributed under the terms of the Creative Commons Attribution License, which permits unrestricted use, distribution, and reproduction in any medium, provided the original author and source are credited. 


\section{Methods}

This cross sectional study (with an analytic element) was conducted in Baghdad city (the capital of Iraq) during the period from February through May 2012.

\section{Study sample}

The target population was adolescent boys that were collected from secondary schools. Central Organization for Statistics (2010-2011) recorded a total of 5,472 secondary schools in Iraq with $1,953,766$ enrolled students. In the same academic year, Baghdad governorate had 1,074 secondary schools, 436 for female students, 532 for males and 106 mixed gender schools. The total number of secondary school students in Baghdad was 543,450, including 243,670 girls and 299,780 boys [17]. The City of Baghdad is divided by Tigris river into two major parts; Russafa to the east and Karkh to the west. Each part has three educational directorates. A simple random sampling technique was adopted for this study through choosing three secondary schools (for boys) from each directorate. The researchers considered including different residential sectors to insure the inclusion of different socio economic strata (elite, public, and suburban) to make the sample more representative and to avoid confounding the results by the socio economic status. Consequently, nine schools from each side of Baghdad city (forming a total of 18 secondary schools) were included. Secondary schools in Iraq usually include six grades and the students' spectrum of age is between 13-18 years. Three classes (using a simple random sampling technique) were chosen from each school (first, third and fifth grades) to include a wide spectrum that represent the targeted age group. All the students in the chosen classes were included in the study yielding a total sample of 1858 boys out of 9100 students enrolled in these schools.

It is worth to mention here that the teenager were not been targeted for being school students but as an age group; cause it is more convenient and practical to collect such a sample of adolescents from schools than through a house to house method.

\section{Survey instrument}

The Mini International Neuropsychiatric Interview PTSD module 'I' (M.I.N.I) was adopted to assess PTSD. M.I.N.I is an internationally validated instrument with an Arabic version; PTSD is rated on 13 items [21]. Data was also collected regarding socio-demographic variables including age, householder of the family, if either of the child or adolescent's parents was deceased, if the student was working, the birth order of the student in his family and the student's school performance measured by the number of lost academic years or failure in any school year. Face to face interview was undertaken. Identification of PTSD in those students was based not on clinical diagnosis but, rather, on probable PTSD symptomatology based on M.I.N.I scale.

An initial two questions were presented: the first confirms exposure to traumatic events such as violent crimes (terrorism attack, kidnapping, arrest, hostage, rape, and witnessing killing of family members or other people), the second question confirms the adolescent's reaction to trauma, expressed as fear, terror and feeling of helplessness. If the answer to these two initial questions was 'No' then no further assessment took place and the subject was not considered to have PTSD. Adolescents who reported 'Yes' to the two initial questions were asked to respond to the rest of the questionnaire. Yes or No was the choice of response to all other questions. The first group of questions was about avoidance symptoms e.g. avoids thinking of events that remind the adolescent of trauma, difficulty in remembering the important details of the event, loss of activities and social isolation. The second question group inquired about post traumatic event symptoms including; hyperarousal symptoms: difficulty in sleeping, obvious tension or suffering from bouts of anger, difficulty in concentration, and nervous and rapid startle responses. Three 'Yes' responses from the first group of questions and two 'Yes' responses from the second group were needed to confirm the presence of PTSD. The interview was done by one of the researchers; a postgraduate family physician, each interview took between 5-7 minutes.

\section{Ethical review}

Although institutional review boards were not available in the conflict - disrupted area of Baghdad, the study was approved by the regional Iraqi Ministry of Education and the Department of Community Medicine at Iraqi Commission for Medical Specializations and Mustansiriya Medical College in Baghdad. The data form was anonymous. A consent from the students and their families was obtained after explaining to them the purpose of this study, giving them the complete choice to participate or not, and telling them that all the information collected will be kept strictly confidential and will not be used for any purpose other than research work. Data was collected via face to face interviews in the presence of the class teacher for security reasons; the teacher was kept in a distance to insure more privacy and freedom for the students to express their responses.

\section{Statistical analyses}

Descriptive statistics were generated from the collected data through the IBM SPSS 19 (Chicago, IL) statistical program. Logistic regression analysis was also done; categorical variables (age, years of school failure and householder) were arranged as binary variables (e.g. less than15years age, year failure, not living with the biological parents).

\section{Results}

\section{Descriptive statistics}

The total sample was 1858 male students, all of whom responded to the survey. This sample represents $20 \%$ of all the students from 18 chosen schools. The adolescents' responses to the M.I.N.I symptoms scale for PTSD showed that the number of adolescents who had experienced traumatic events was 1026 (55.2\% of the total sample). Traumatic- reaction symptoms like fear and/ or terror and painful recall of traumatic events retrieved by $37 \%$ of the sample. The total number of the students who met the M.I.N.I criteria for PTSD was 317, representing a prevalence of $17.1 \%$ of the total sample.

\section{Analytic statistics}

Table 1 illustrates PTSD prevalence rates according to risk variables (age, parent's presence, house holder status, and impact of working during school courses). This shows a linear prevalence rate with age, it is lowest in the age 13 year subgroup (12.7\%) and highest among subgroup aged (17-19) year at $26.4 \%$. The association between age and PTSD was statistically significant $\left(\chi^{2}=29.36, p=.001\right)$. The total number of boys with a deceased father was 135 from the total sample, of them 46 (34\%) have PTSD versus $15.7 \%$ among adolescents subgroup with live father. Statistically, there was a significant association with the fatherdeath variable $\left(\chi^{2}=29.78, p<.001\right)$ in comparison to the mother - death variable $\left(\chi^{2}=1.94, p=.28\right)$. The prevalence of PTSD among adolescents who lived with a father as the only householder was $28 \%$, nearly $20 \%$ when mother is the only house holder, while it was $29.5 \%$ where none of the biological parents was the householder $\left(\chi^{2}=23.67, \mathrm{p}=.001\right)$. Results showed that $49.2 \%$ of the PTSD children were the first-born in their 


\begin{tabular}{|c|c|c|c|c|c|c|c|}
\hline \multicolumn{2}{|l|}{ Risk variable } & PTSD & No PTSD & $\begin{array}{c}\text { Total } \\
\text { in subgroup }\end{array}$ & $\begin{array}{l}\text { Prevalence of PTSD in } \\
\text { subgroup (\%) }\end{array}$ & $\begin{array}{c}P \\
\text { value }\end{array}$ & $X^{2}$ \\
\hline \multirow{5}{*}{ Age per year } & 13 & 13 & 89 & 102 & $(12.74)$ & \multirow[b]{5}{*}{0.001} & \multirow[b]{5}{*}{29.36} \\
\hline & 14 & 105 & 627 & 732 & $(14.34)$ & & \\
\hline & 15 & 104 & 522 & 626 & $(16.61)$ & & \\
\hline & 16 & 49 & 175 & 224 & $(21.87)$ & & \\
\hline & $17-19$ & 46 & 128 & 174 & $(26.43)$ & & \\
\hline \multirow[b]{2}{*}{ Father's condition } & Alive & 271 & 1452 & 1723 & $(15.72)$ & \multirow[b]{2}{*}{$<0.001$} & \multirow[b]{2}{*}{29.78} \\
\hline & Dead & 46 & 89 & 135 & $(34.07)$ & & \\
\hline \multirow[b]{2}{*}{ Mother's condition } & Alive & 306 & 1504 & 1810 & $(16.9)$ & \multirow[b]{2}{*}{0.28} & \multirow[b]{2}{*}{1.94} \\
\hline & Dead & 11 & 37 & 48 & $(22.91)$ & & \\
\hline \multirow{4}{*}{ House holder } & Father \& Mother & 223 & 1252 & 1475 & $(15.11)$ & \multirow{4}{*}{0.001} & \multirow{4}{*}{23.67} \\
\hline & Mother only & 41 & 158 & 199 & $(20.6)$ & & \\
\hline & Father only & 35 & 88 & 123 & $(28.45)$ & & \\
\hline & Other relatives & 18 & 43 & 61 & $(29.5)$ & & \\
\hline \multirow{2}{*}{ Working during school time } & Yes & 92 & 303 & 395 & $(23.29)$ & \multirow[b]{2}{*}{0.001} & \multirow[b]{2}{*}{13.76} \\
\hline & No & 225 & 1238 & 1463 & $(15.37)$ & & \\
\hline
\end{tabular}

Table 1: Distribution of PTSD cases according to variable risk factors, $N=1858, P T S D$ total $n=317$.

\begin{tabular}{|c|c|c|c|c|c|c|c|c|}
\hline \multirow{2}{*}{ Variable } & \multirow{2}{*}{ B } & \multirow{2}{*}{ S.E } & \multirow{2}{*}{ Wald } & \multirow{2}{*}{ df } & \multirow{2}{*}{ Sig } & \multirow{2}{*}{ OR } & \multicolumn{2}{|c|}{$95 \% \mathrm{Cl}$ for OR } \\
\hline & & & & & & & Lower & Upper \\
\hline Age (>15) & -0.792 & 0.236 & 11.249 & 1 & 0.001 & 2.207 & 1.391 & 3.509 \\
\hline School year failure & 0.363 & 0.225 & 2.615 & 1 & 0.106 & 1.438 & 0.926 & 2.234 \\
\hline Father's Death & -1.126 & 0.201 & 31.486 & 1 & 0.0001 & 3.086 & 2.079 & 4.566 \\
\hline mother's Death & -0.494 & 0.369 & 1.793 & 1 & 0.181 & 1.639 & 0.794 & 3.378 \\
\hline not live with the biological parents & -0.523 & 0.195 & 7.193 & 1 & 0.007 & 1.686 & 1.150 & 2.469 \\
\hline Working at school time & 0.483 & 0.151 & 10.239 & 1 & 0.001 & 0.617 & 0.459 & 0.829 \\
\hline Eldest Son & 0.524 & 0.128 & 16.739 & 1 & 0.0001 & 1.689 & 1.314 & 2.172 \\
\hline Constant & 0.659 & 0.657 & 1.007 & 1 & 0.316 & 1.933 & - & - \\
\hline
\end{tabular}

Table 2: Logistic Regression Analysis of the studied variables.

families. There was a statistically significant association between PTSD and working during school courses $\left(\chi^{2}=13,76, p=.001\right)$. The results also showed that $21.1 \%$ of PTSD cases failed to complete one academic year, and $12.3 \%$ failed in two school years or more (not tabulated).

\section{Logistic regression}

Analysis of the studied variables revealed that father's death and age of more than fifteen years were risk factors for developing PTSD. Also, mother's death, being the eldest son, and not living with the biological parents were all risk factors, while odds ratio of boys working during school time was associated with less risk of PTSD (Table 2).

\section{Discussion}

In this study the prevalence rate of PTSD among male adolescents (13-19 years) in Baghdad was measured as $17.1 \%$. This is not dissimilar to other reported figures in areas of wars and conflicts, 13, 9 and is higher than that found in peace time settings from $0.3 \%$ to $6.1 \%$ [22]. The National Survey of Adolescents shows a PTSD prevalence of $3.7 \%$ among boys in the US [23]. In Switzerland a rate of $2.4 \%$ among male adolescents is reported [24]. The PTSD rate in Iraqi male children during 2005-2006 was 9\% [25], when violence dominated life in Iraq. This figure is lower than this survey's figure which was conducted nearly ten years after the 2003 invasion of Iraq; this may reflect the continuous state of the unsafe and risky environment in Iraq in spite of the current apparent improvement in security.

The results of the current study showed that the prevalence of PTSD is increasing with age; the highest rate was at age 17-19 years (26.4\%). This may reflect the ongoing stress experienced by the older adolescents and their greater appreciation of the ongoing risks to their security. These numbers also might be due to the fact that there is a great difference between man- made disaster and natural disasters in the apprehension of older and younger children. The older ones most probably are less vulnerable to natural disasters, though, in contrast, more vulnerable to man- made disasters.

A study on risk factors for PTSD examined in adolescents 12-17 years in Gaza-Palestine showed that PTSD was more prevalent among older adolescents in both genders [26]. In contrast to these findings, a study of Iranian adolescents who experienced the consequences of 2009 earthquake; showed that $51.6 \%$ of the children younger than 15 years displayed PTSD versus $36.3 \%$ of adolescents [27].

Boys who lost one or both parents and those who were living with non-biological caregivers presented with higher rates. Loss of family care and protection plays a significant role in PTSD expression. The association between long term effects of war related trauma in children and the experience of their fathers' absence has been supported in a study of war-related trauma among children in Kuwait during the Gulf war in 1991 [28]. The relation of not living with a biological parent and the risk of trauma exposure are also supported from findings in more peaceful areas, however, gender differences have not been found [24].

Our study revealed a high prevalence of PTSD among eldest sons in the families; this may indicate higher psychological demands and responsibilities on the eldest boys that may lead to a high probability of trauma exposure. Children and adolescents in Iraq usually do not work during school time; one of the major negative consequences of long-term wars and conflicts is that they lead to severe deprivation and increased poverty rates among Iraqi families. Young boys have been forced to work exposing them to high risk environment and 
trauma $[16,29]$. This is consistent with the current study where there was a higher rate of PTSD among the working group. There is a linear association between PTSD and working during school courses. However surprisingly; the odds ratio calculation in the current study shows that working during school time is associated with less PTSD. Although this seems to be contradictive but it has an intrinsic logic: working boys are more exposed to risks but those who are severely affected by PTSD will possibly not be able to continue working.

School achievement in relation to PTSD has also been explored in this study. The results demonstrated an association of a high prevalence rate with a one year failure in school at $21.1 \%$ while $12.3 \%$ had two years or more of failure. This may suggest that low ability pupils are more prone to PTSD reactions than more capable students or that impaired psychological status due to PTSD has reduced child academic performance. The literature has addressed the effects of trauma on the cognitive abilities of children including academic difficulties [30].

The most prominent finding from this study is that more than half of the total sample had reported multiple experiences of trauma. Around $37 \%$ reported traumatic- reaction symptoms like fear and/ or terror and the painful recall of traumatic events. This represents an urgent need to provide adolescents with early psychological care services.

\section{Limitations}

There were two main limitations in the current study: first, conducting researches by itself is a risk to the lives of researchers in Baghdad, the un-favorite security condition narrows the choices of sample selection making it difficult to choose a house to house method in data collection so we shifted to the secondary schools to collect the targeted age group from there, second; It is extremely sensitive in Iraq (at the present era) to survey adolescent girls for such an issue, that's why the study was limited to boys only.

In summary, the data from this study suggest that there are multiple factors contributing to the occurrence of PTSD among Iraqi male adolescents. This may serve as a foundation for further research in this crucial field of adolescents' mental health in the context of armed conflict. The urgent need to develop adolescents' mental health care services in Iraq is supported by our study. There may be an even greater need for school-based programs to promote child and adolescent mental health. It is essential to build the capacity of Iraqi educational professionals through continuing health and medical educational opportunities, and to train Iraqi teachers in recognizing children's distress and in applying appropriate strategies that address children's needs, particularly as Iraqi children and adolescents continue to be exposed to social instability and violence, and the most distressing lifetime traumas [16,31].

\section{References}

1. Bedard M, Greif JL, Buckley TC (2004) International publication trends in the traumatic stress literature. J Trauma Stress 17: 97-101.

2. Iribarren J, Prolo P, Neagos N, Chiappelli F (2005) Post-traumatic stress disorder: evidence-based research for the third millennium. Evid Based Complement Alternat Med 2: 503-512.

3. Fu Y, Chen C, Wang J, Tang X, He J, et al. (2013) Analysis of prevalence of PTSD and its influencing factors among college students after the Wenchuan earthquake. Child \& Adolescent Psychiatry \& Mental Health, 7:1

4. Yasan A, Saka G, Ozkan M, Ertem M (2009) Trauma type, gender, and risk of PTSD in a region within an area of conflict. J Trauma Stress 22: 663-666.

5. Attanayake V, McKay R, Joffres M, Singh S, Burkle F Jr, et al. (2009) Prevalence of mental disorders among children exposed to war: a systematic review of 7,920 children. Med Confl Surviv 25: 4-19.
6. Murthy RS, Lakshminarayana R (2006) Mental health consequences of war: a brief review of research findings. World Psychiatry 5: 25-30.

7. Allwood MA, Bell-Dolan D, Husain SA (2002) Children's trauma and adjustment reactions to violent and nonviolent war experiences. J Am Acad Child Adolesc Psychiatry 41: 450-457.

8. Neugebauer R, Fisher PW, Turner JB, Yamabe S, Sarsfield JA et al. (2009) Post-traumatic stress reaction among Rwandan children and adolescents in the early aftermath of genocide. Int J Epidemiol 38: 1033-1045.

9. Miller T, el-Masri M, Allodi F, Qouta S (1999) Emotional and behavioura problems and trauma exposure of school-age Palestinian children in Gaza: some preliminary findings. Med Confl Surviv 15: 368-378.

10. Qouta S, Punamäki RL, El Sarraj E (2003) Prevalence and determinants of PTSD among Palestinian children exposed to military violence. Eur Child Adolesc Psychiatry 12: 265-272.

11. Thabet AA, Vostanis $P$ (1999) Post-traumatic stress reactions in children of war. J Child Psychol Psychiatry 40: 385-391.

12. Cardozo BL, Bilukha OO, Crawford CA, Shaikh I, Wolfe MI, et al. (2004) Menta health, social functioning, and disability in postwar Afghanistan. JAMA 292 $575-584$.

13. Catani C, Schauer E, Elbert T, Missmahl I, Bette JP, et al. (2009) War trauma, child labor, and family violence: life adversities and PTSD in a sample of school children in Kabul. J Trauma Stress 22: 163-171.

14. Bronstein I, Montgomery P, Dobrowolski S (2012) PTSD in asylum-seeking male adolescents from Afghanistan. J Trauma Stress 25: 551-557.

15. WHO (2009) Iraq mental health survey 2006/7 report. Geneva: World Health Organization.

16. AlObaidi AK (2013) Psychological Trauma: Experience from Iraq. J Trauma Treat 5: 1-2.

17. Central Organization for Statistics (2011) Annual abstract of statistics 2010 2011.

18. AlObaidi, AK., Corcoran T, carth L (2013) Psychosocial Research with Children in Iraq- Current Health Practice and Policy in a Context of Armed Conflict. International Psychiatry, 10: 72-74.

19. WHO/Iraqi MoH (2006) WHO-AIMS Report on Mental Health System in Iraq Iraqi Ministry of Health, Baghdad, Iraq.

20. AlObaidi AK, Nelson D, AlBadawi G, Hicks HR, Guarine AJ (2013) Child Menta Health and Service Needs in Iraq: Beliefs and Attitudes of Primary Schoo Teachers. Child and Adolescent Mental Health, 18: 171-179.

21. Sheehan DV, Lecrubier Y, Sheehan KH, Amorim P, Janavs J, et al. (1998) The Mini-International Neuropsychiatric Interview (M.I.N.I.): The development and validation of a structured diagnostic psychiatric interview for DSM-IV and ICD10. J Clin Psychiatry 59:22-33.

22. Kessler RC, Ustun TB (Eds.) (2008).The WHO World Mental Health Surveys: global perspectives on the epidemiology of mental disorders, Cambridge University Press, Newyork

23. Kilpatrick DG, Ruggiero KJ, Acierno R, Saunders BE, Resnick HS, et al. (2003) Violence and risk of PTSD, major depression, substance abuse/dependence and comorbidity: results from the National Survey of Adolescents. J Consult Clin Psychol 71: 692-700.

24. Landolt MA, Schnyder U, Maier T, Schoenbucher V, Mohler-Kuo M (2013) Trauma exposure and posttraumatic stress disorder in adolescents: a national survey in Switzerland. J Trauma Stress 26: 209-216.

25. Razokhi AH, Taha IK, Taib NI, Sadik S, Al Gasseer N (2006) Mental health of Iraqi children. Lancet 368: 838-839.

26. Kolltveit S, Lange-Nielsen II, Thabet AA, Dyregrov A, Pallesen S, et al. (2012) Risk factors for PTSD, anxiety, and depression among adolescents in Gaza. J Trauma Stress 25: 164-170.

27. Parvaresh N, Bahramnezhad A (2009) Post-traumatic stress disorder in bamsurvived students who immigrated to Kerman, four months after the earthquake. Arch Iran Med 12: 244-249.

28. Hadi F, Llabre MM, Spitzer S (2006) Gulf War-related trauma and psychological distress of Kuwaiti children and their mothers. J Trauma Stress 19: 653-662.

29. Al-Obaidi AK, Piachaud J (2007) While adults battle, children suffer: future problems for Iraq. J R Soc Med 100: 394-395. 
Citation: Lafta RK, Aziz ZS, AlObaidi AK (2014) Posttraumatic Stress Disorder (PTSD) among Male Adolescents in Baghdad. J Psychol Abnorm Child 3: 121. doi:10.4172/2329-9525.1000121

30. Armsworth MW, Holaday M (1993) The Effects of Psychological Trauma on Children and Adolescents. Journal of Counseling \& Development 72: 49-56.
31. AlObaidi AK, Budosan B, Jeffery L (2010) Child and adolescent mental health in Iraq: current situation and scope for promotion of child and adolescent mental health policy. Intervention 8: 40-51. 